\title{
MULTI-OBJECTIVE PARTICLE SWARM OPTIMIZATION OF THE K-TYPE SHELL AND TUBE HEAT EXCHANGER (CASE STUDY)
}

\author{
M. Nadi ${ }^{1}$, M.A. Ehyaei ${ }^{1 *}$, A. Ahmadi ${ }^{2}$, O. E. Turgut ${ }^{3}$
}

\begin{abstract}
This paper investigated optimization of two objectives function include the total amount of heat transfer between two mediums and the total cost of shell and tube heat exchanger. The study was carried out for k-type heat exchanger of the cryogenic unit of gas condensates by multiple objective particle swarm optimization. Six decision variables including pipe pitch ratio, pipe diameter, pipe number, pipe length, baffle cut ratio, and baffle distance ratio were taking into account to conduct this simulation-based research. The results of mathematical modeling confirmed the actual results (data collected from the evaporator unit of the Tehran refinery's absorption chiller). The optimization results revealed that the two objective functions of heat transfer rate and the total cost were in contradiction with each other. The results of the sensitivity analysis showed that with change in the pitch ratio from 1.25 to 2 , the amount of heat transfer was reduced from 420 to $390 \mathrm{~kW}$ about $7.8 \%$. Moreover, these variations caused reduction in cost function from 24,500 to $23,500 \$$, less than $1 \%$. On the other hand, an increase in pipe length from 3 to 12 meters, the heat transfer rate raised from 365 to $415 \mathrm{~kW}$ by $13.7 \%$, while the cost increased from $20,000 \$$ to $24500 \$$ about $22 \%$.
\end{abstract}

Keywords: Cryogenic, Heat exchanger, Optimization, Objective

\section{INTRODUCTION}

In recent years, there is growing research on the application of optimization algorithms to solve the problems related to the heat exchanger and power generation units [1-14]. For example, some researchers examined the cost minimization of the $t$ of initial investment based on the surface area of heat as the objective function [15]. While a number of other researchers considered the total cost including the initial investment cost on basis of the surface area of heat transfer plus the current costs including pumping cost as the objective function [16-21].

In other cases, by a number of researchers, the entropy generation is chosen as the objective function [22-24]. Application of GA (genetic algorithm) in heat exchanger optimization has been extensively considered by many researches taking into account of one, two and three objective functions [16, 18, 25-32].

Patel et al. [33] conducted a research on the shell and tube heat exchanger optimization using the particle swarm optimization (PSO). (PSO). In this study, the optimization results were compared with those found by the genetic algorithm, which demonstrate that the PSO algorithm has better predictive performance than the genetic algorithm. Dastmalchi et al. [34] investigated PSO algorithm for finned tubes in double pipe heat exchanger. Their results showed that the optimum height of fin was increased with increasing Reynolds number.

Sahin et al. [35] used the bee colony algorithm with design and optimize the shell and tube heat exchanger (STHE) in order to reduce the overall cost. The results of this study showed that the total cost of the heat exchanger can be reduced from $64480 \$$ to $50793 \$$ with utilizing the proposed optimization procedure. Zarea et al. [36] also used bee colony algorithm to optimize a plate fin heat exchanger. He concluded that this algorithm has better performance compared to other optimization algorithms mentioned in the associated paper. paper. Accordingly, in another study [36], they combined the mutation schemes of the Bees and PSO algorithms to optimize a heat exchanger of this type.

This paper was recommended for publication in revised form by Regional Editor Mohammad Safaei ${ }^{1}$ Department of Mechanical Engineering, Pardis Branch, Islamic Azad University, Pardis New City, Iran ${ }^{2}$ School of New Technologies, Iran University of Science \& Technology, Islamic Republic of Iran ${ }^{3}$ Department of Mechanical Engineering, Faculty of Engineering, Bakircay University, Menemen/ Izmir, Turkey *E-mail address: aliehyaei@yahoo.com Orcid id: 0000-0003-3980-9109, 0000-0002-4721-9427, 0000-0003-2652-6011, 0000-0003-3556-8889 Manuscript Received: 26 January 2019, Accepted: 5 February 2019 
Azad and Amidpour [37] conducted the optimization of the STHE based on the structural theory. This theory was inspired by nature and was a new method of optimization in engineering applications. The results of this study showed a 50 percent reduction in total cost.

Rao and Patel [38] used a training optimization algorithm and selecting multiple independent variables to optimize heat transfer rate of STHE and a flat plate heat exchanger. Fetaka et al. [39] used nine independent variables in order to carry out heat exchange process under predefined imposed heat load. In this study, they selected non dominated sorting genetic algorithm (NSGA - 2) and compared their results with a research with one objective function [40]. They concluded that optimization with two objective functions has a better result. Other related studies on the optimization of heat exchanger with this algorithm were reported in literature $[41,42]$.

Rao et al. [43] used the particle swarm optimization algorithm for optimization of heat exchanger with the design objectives of entropy generation, heat exchanger volume and annual cost of the mentioned heat exchanger. In this study, they obtained at least the volume of $0.0106 \mathrm{~m}^{3}$ heat exchanger, and at least the annual cost of $3018 \$$ and minimum entropy production unit of $0.053 \mathrm{~J} / \mathrm{kg} \mathrm{K}$.

In another study Rao and Saroj [44] proposed a new method of optimization which called elitist-Jaya algorithm. They concluded that this algorithm is better than other optimization algorithms. Also in another study associated with heat exchanger design, literature [45] they optimized a shell and tube heat exchanger with the proposed Jaya algorithm. In this analysis, they considered sedimentation of heat exchanger. They compared the results with other optimization methods such as genetic algorithm (GA), particle swarm optimization (PSO) and civilized swarm optimization (CSO). They concluded that this Jaya optimization has better results.

Segundo et al. [46] proposed an economic optimization of shell and tube heat exchanger by Tsallis differential evolution. They concluded that by using this method, total annual cost of the heat exchanger is reduced in the varying ranges between 27 to $55 \%$.

Etghani and Baboli [47] utilized Taguchi method to carry out an optimization of a helical tube heat exchanger. In this study they considered exergy loss and total heat transfer rate as two optimization objectives and concluded that tube diameter and cold fluid mass flow rate have the most effect on exergy loss.

Several studies were conducted by Raja et al. about the optimization of heat exchanger with heat transfer search algorithm [48-50].

Turgut [51] did an optimization of shell and tube heat exchanger with a combination of backtracking search (BSA) and sine-cosine algorithm (SCA) algorithms. He compared this method of optimization with other optimization methods applicable in mechanical engineering.

In this study, two objective functions of total heat load and total heat exchanger costs are optimized simultaneously. In two objective functions, the answer is curve composed of non- dominated optimal solutions rather than a single optimum point. It should be mentioned the total cost include both investment cost and operational costs which accounts for the influences of the many auxiliary equipment. So far, there has been accomplished few comprehensive studies aiming to investigate two conflicting objective functions as well as sensitivity analysis for individual variables in a k-type of STHE at low temperature fluid. The mathematical model, type of heat exchanger and heat exchanger specification are considered in reference [16, 51-54]. In industry level, optimization of heat exchanger helps to reduction of energy consumption. Also, by multi-objective optimization instead of one optimized point, gives a graph (Pareto front) the user can select the best answer considering technical and economical point of views. For further research, combination of optimization algorithms can be considered.

The innovations of this research are:

- Definition of two objective functions and six variables for k-type STHE

- Optimization of k-type of STHE by MOPSO algorithm

- Sensitivity analysis for the independent decision variables 


\section{MATHEMATICAL MODELING}

For a typical STHE, The following assumptions are considered in this analysis [51]:

- The evaporative fluid is R134A

- The coolant water is in the direction of the shell.

- R134 is delivered into the tubes in the form of saturated fluid, which is the quality of the coolant (cooler) at the pipe inlet section is $0.0(\mathrm{x}=0.0)$.

- The Gungor-Winterson flow rate is used in order to calculate the heat transfer coefficient of the pipe side.

- The flow and temperature of the cold and hot fluid are considered as the input data of the modeling.

Detailed mathematical modeling is based on [51].

The required parameters to compute the total cost $\mathrm{Ce}, \mathrm{H}, \eta, \mathrm{i}$, ny are $0.00012 \$ / \mathrm{Wh}, 7000 \mathrm{~h}, 0.9,10 \%$ and 20 years, respectively.

The operational conditions of the current heat exchanger with the physical properties of the hot and cool fluid and the deposition resistance on the shell and the tube are presented in the following table. The modeling and the optimization carried out according to these operating conditions [51].

Table 1. The operational conditions for the studied converter.

\begin{tabular}{|c|c|c|c|c|}
\hline Description & Unit & \multicolumn{2}{|c|}{ Tube side } & Shell side \\
\hline Fluid & $(-)$ & \multicolumn{2}{|c|}{ R134a } & water \\
\hline Fluid Stream Type & $(-)$ & \multicolumn{2}{|c|}{ Cold stream } & Hot stream \\
\hline Mass flow rate & $(\mathrm{kg} / \mathrm{s})$ & \multicolumn{2}{|c|}{1.62} & 5.35 \\
\hline Inlet temperature $\mathrm{T}^{\mathrm{i}}$ & $\left({ }^{\circ} \mathrm{C}\right)$ & \multicolumn{2}{|c|}{7} & 26 \\
\hline Outlet temperature $\mathrm{T}^{\mathrm{o}}$ & $\left({ }^{\circ} \mathrm{C}\right)$ & \multicolumn{2}{|c|}{7} & - \\
\hline Fouling resistance $r$ & $\left(\mathrm{~m}^{2} \mathrm{~K} / \mathrm{W}\right)$ & \multicolumn{2}{|c|}{0.000176} & 0.000176 \\
\hline Fluid Phase & $(-)$ & Vapor & liquid & liquid \\
\hline Density $\rho$ & $\left(\mathrm{kg} / \mathrm{m}^{3}\right)$ & 18.32 & 1271.3 & 998 \\
\hline Constant pressure specific heat $c_{p}$ & $(\mathrm{~kJ} / \mathrm{kg} \mathrm{K})$ & 929.9 & 1361.7 & 4182 \\
\hline Dynamic viscosity (Pa.s) & (Pa.s) & $1.01 \mathrm{E}-5$ & $2.48 \mathrm{E}-4$ & $9.59 \mathrm{E}-4$ \\
\hline Thermal conductivity & $\left(\mathrm{W} / \mathrm{m}^{2} \mathrm{~K}\right)$ & 0.12 & 0.088 & 0.606 \\
\hline
\end{tabular}

\section{PARTICLE SWARM OPTIMIZATION ALGORITHM (PSO)}

In this topic, finding the optimum and the best acceptable solution for the given constraints and requirements of the problem is the main goal. For a given problem, maybe there are many different answers which could be obtained after the completed iterations. After that, these results should be compared to find the optimal solution, therefore this function is called the objective function [55].

The choice of this function depends on the nature of the problem and finding the proper objective function is one of the most important steps of optimization. In some occasion several objective functions are needed at the same time, such optimization issues are called multi - objective functions [55].

The simplest way to deal with such issues is to form a new objective function as a linear combination of the main objective functions, in which the effect of each function is determined by the weighting factors assigned to it. The second method consider both objective functions individually. In this case, instead of one point, a Pareto front (an optimal solution set) is achieved [55]. 
Each optimization problem has a number of independent variables called design variables or decision variables. The goal of optimization is to determine the design variables is to minimize or maximize objective function. In the optimization method, all feasible solutions and optimal solutions are defined. Optimization algorithms cover both maximization and minimization problems. Because the maximization problem is capable to be converted to minimization problem (by multiply the objective function in a negative sign) [55].

The PSO model is designed to investigate the sudden movement in the flight of birds, and to analyze the flight patterns by the optimal shape of cloud particles in the space. By careful study, the shift of the particle path from the flight pattern to its neighbors is concerned, each particle taking a pattern from another particle to move in the same way [55].

PSO optimization is one of the group optimization algorithms that operate on the basis of the random generation of the initial population. This algorithm is based on the modeling and simulation of the collective and mass fly behavior (group) of birds or mass movements (group) of fish [55].

Each member in the group is defined by the velocity vector and the position vector in the search space. In each iteration, the new position of the particles is defined due to the velocity vector and the position vector in the search space. At each iteration, the new position of the particles is updated according to the current velocity vector, the best location found by the particle and the best position found by the best particle in the group. This algorithm was initially defined for continuous parameters, but it is also extended to discrete state by considering that we deal with discrete parameters in some applications [55].

The implementation steps of the PSO algorithm are as follows [55]:

1. Random production of elementary particles

2. Choosing the number of elementary particles

3. Evaluation of objective function (based on cost or fitness function) of birds

4. Record of the best position for each particle as well as the best position among the entire particles

5. Convergence test

\section{RESULTS AND DISCUSSION}

Before optimizing, it is necessary to measure the validity of the mathematical model. In this regard, the results obtained from the model are compared with the actual results collected from evaporator unit of the Tehran refinery's absorption chiller. For this purpose, input data according to model with realistic HE data are considered and output variables such as heat transfer and pressure drop in the both sides of the STHE are calculated by the model. Finally, the actual results, which are collected from evaporator unit of the Tehran refinery's absorption chiller are compared with the modeling results and the percentage of errors are presented. The following results were obtained by virtue of the mathematical model presented in the preceding sections as well as in terms of the reported operational conditions above. As it can be seen, the error percentage in predicting the pressure drop across the tube and the shell is about 6 $\%$ and $8 \%$, respectively. In addition, deviation between actual and predicted heat transfer between the hot and cold fluid is about $5 \%$. The numerical results of the model validation are presented in Table 2 [56].

Table 2. Validation of the results of the mathematical modeling of the pipe shell.

\begin{tabular}{|c|c|c|c|}
\hline Variable & Modeling value & Real value & Error \% \\
\hline$(\mathrm{Pa})$ Tube pressure loss & 14788 & 15700 & $6 \%$ \\
\hline$(\mathrm{Pa})$ Shell pressure loss & 7505 & 8097 & $\mathbf{8 \%}$ \\
\hline$(\mathrm{kW})$ Heat transferred & 318.1 & 302.8 & $5 \%$ \\
\hline
\end{tabular}

The results of the validation on graph are presented in the Figure 1. 

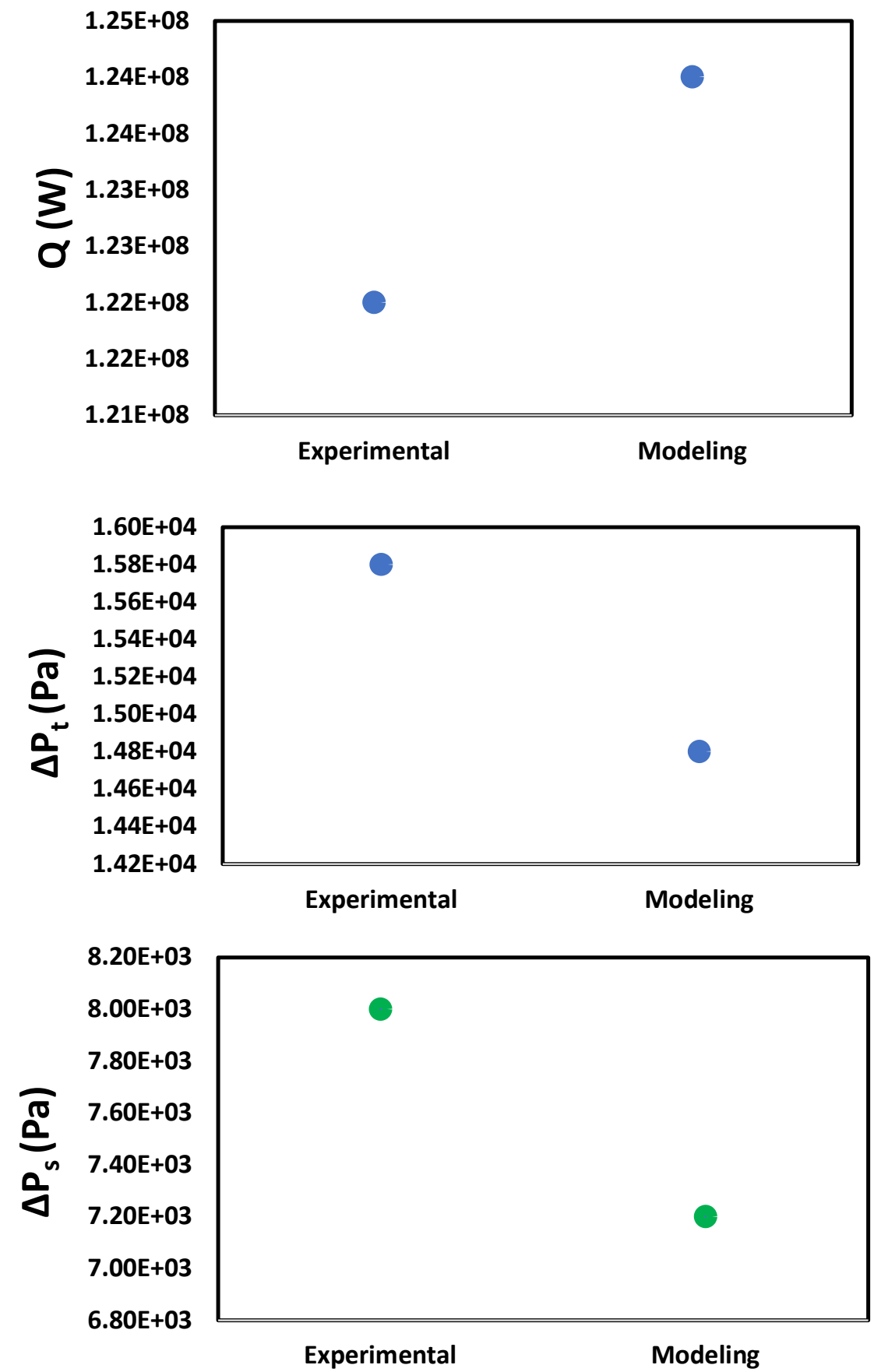

Figure 1. The validation graph of the modeling results of the pipe shell converter.

As it can be seen, the difference between the results of the model and the experimental results for the pressure drop for the shell and tube side as well as the heat transferred is low and insignificant. The actual pressure drop for the tube and shell side is around 15700 and $8097 \mathrm{~Pa}$, while the pressure drop was calculated for the tube and the shell at about 14788 and $7505 \mathrm{~Pa}$. Also, the amount of heat exchanged experimentally was obtained at about $122 \mathrm{MW}$, while it was calculated to model the value of $124 \mathrm{MW}$. So three important parameters of model were compared with experimental data acquired from the daily report of factory. They have a good agreement. 
In this paper, six independent variables are considered based on the geometrical dimensions of the heat exchanger. These six variables influence the considered two objective functions of the problem, the function of heat transfer rate and the function of cost would change. These dependent variables and independent variables are represented by the following relationships.

$$
\begin{gathered}
Q=f\left(d_{o}, L, N, P_{R}, B s, L_{c}\right) \\
\operatorname{Cost}(\&)=g\left(d_{o}, L, N, P_{R}, B s, L_{c}\right)
\end{gathered}
$$

In this paper, the design constraint on the fluid pressure drops over the tube and the shell side as well as constraints on the period of change are considered as independent variables. In Tables 3 and 4 the constraints and limitations of the independent variables and pressure drop are presented as below:

Table 3. Constraints and constraints on the independent variables

\begin{tabular}{|c|c|c|c|}
\hline Variable & Decision variable & Lower bound & Upper bound \\
\hline $\mathrm{d}_{\mathrm{o}}$ & Tube Outer diameter $(\mathrm{mm})$ & 10 & 25 \\
\hline $\mathrm{N}_{\mathrm{t}}$ & Number of tube & 50 & 500 \\
\hline $\mathrm{L}$ & Tube length $(\mathrm{m})$ & 3 & 12 \\
\hline $\mathrm{Pt} / \mathrm{d}_{\mathrm{o}}$ & Pitch tube ratio & 1.25 & 2 \\
\hline $\mathrm{L}_{\mathrm{C}} / \mathrm{D}_{\mathrm{s}}$ & Baffle cut ratio & 0.2 & 0.32 \\
\hline $\mathrm{B} / \mathrm{D}_{\mathrm{s}}$ & Baffle spacing ratio & 0.2 & 1.4 \\
\hline
\end{tabular}

Table 4. Constraint on pressure drop

\begin{tabular}{|c|c|c|c|}
\hline Variable & Decision variable & Lower bound & Upper bound \\
\hline$\Delta \mathrm{p}_{\mathrm{t}}$ & Tube side pressure drop (Bar) & 0 & 1 \\
\hline$\Delta \mathrm{p}_{\mathrm{s}}$ & Shell side pressure drop (Bar) & 0 & 1 \\
\hline
\end{tabular}

Pareto front depicted in Figure 2. shows the best obtained values of the two contradicting objective functions by the proposed MOPSO and non-dominating Pareto - optimal solution. As it can be seen in the following figure, the value of $Q$ (the first objective function: heat transfer rate) is plotted against the $C_{\text {total }}$ (the second objective function: heat exchanger cost. Target is maximizing the $\mathrm{Q}$ and minimizing the $\mathrm{C}_{\text {total }}$. It is clear that increasing the heat transfer rate, increases the cost of heat exchanger and vice versa. It means that if we want a higher heat transfer, the heat exchanger cost is increased.

None of the compiled points in the Pareto frontier are superior to each other. For example, point $\mathrm{A}$ is the optimum value for the total heat load (the first objective function), while the total cost (the second objective function) is undesirable value at its maximum. On the other hand, the point of $\mathrm{D}$, heat load is not desirable, but the cost is desirable (at least possible cost). 


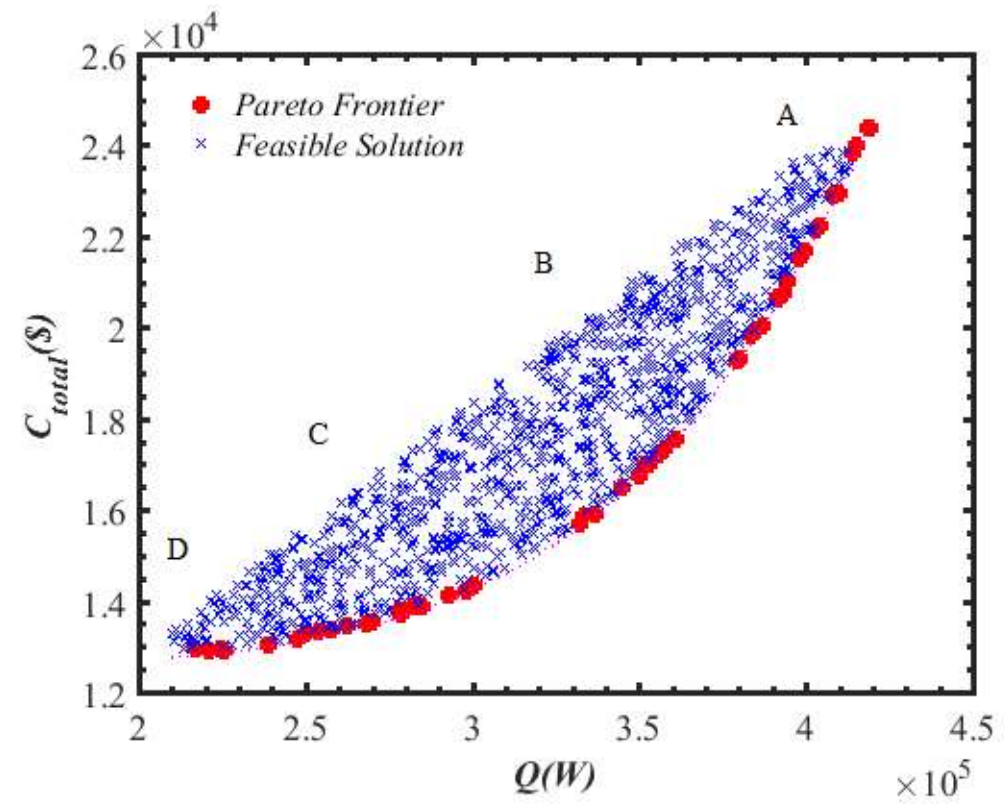

Figure 2. Optimal solutions of the two - objective function for STHE.

Therefore, none of the points A, B, C, D are superior to each other, but among all possible solutions, the best values are achieved along the Pareto frontier. As it can be seen in the figure, the Pareto points provide the lowest possible cost per peak of the heat capacity. Each point in the two dimensional q - cost plane refers to a solution where the calculations are obtained. The numerical results of design variables at two solution points A and D are listed in the following table. The values of the independent variables with values corresponding to the objective functions are presented in this table.

Table 5. Design data for points A and D.

\begin{tabular}{|c|c|c|c|c|c|c|}
\hline Discription & Variable & Unit & A & B & C & D \\
\hline Heat transfer & $\mathrm{q}$ & $\mathrm{kW}$ & 420.0 & 378.7 & 320 & 212.1 \\
\hline Total cost & $\mathrm{C}_{\text {total }}$ & $\$$ & 24630 & 18010 & 14970 & 12810 \\
\hline Tube diameter & $\mathrm{d}_{\mathrm{o}}$ & $\mathrm{mm}$ & 24.9 & 24.9 & 24.9 & 24.9 \\
\hline Number of Tube & $\mathrm{N}_{\mathrm{t}}$ & - & 499 & 391 & 253 & 100 \\
\hline Length of Tube & $\mathrm{L}$ & $\mathrm{m}$ & 11.9 & 9.9 & 7.1 & 4 \\
\hline Tube pitch Ratio & $\mathrm{P}_{\mathrm{t}}$ & - & 1.88 & 1.91 & 1.93 & 2 \\
\hline Baffle cut ratio & $\mathrm{Bs}$ & - & 0.2 & 0.20 & 0.20 & 0.2 \\
\hline Baffle spacing ratio & $\mathrm{L}_{\mathrm{C}} / \mathrm{D}_{\mathrm{S}}$ & - & 0.21 & 0.23 & 0.23 & 0.24 \\
\hline
\end{tabular}

The influence of sensitivity analysis can be used to determine the effect of each independent variable on the dependent variables. In sensitivity analysis, all variables are assumed to be fixed and only one variable is changed in the allowed range. The results are obtained from the sensitivity analysis as they are shown in Table 6 . and Figures 3 to 7 . 
Table 6. The sensitivity analysis of the independent variables at points A, B, and C, D.

\begin{tabular}{|c|c|c|c|}
\hline $\begin{array}{c}\text { Figure } \\
\text { Number }\end{array}$ & $\begin{array}{c}\text { The impact on the cost } \\
\text { function }\end{array}$ & The impact on the q & Independent variable \\
\hline $\mathbf{6}$ & $\begin{array}{r}\text { Decrease with average slope } \\
\text { decrease }\end{array}$ & Decrease with low slope & $\left(\boldsymbol{P}_{\boldsymbol{t}} / \boldsymbol{d}_{\boldsymbol{o}}\right)$ Increasing the tube steps \\
\hline $\mathbf{7}$ & Increase with high slope & Increase with high slope & $(\boldsymbol{L})$ Increasing the length of the tube \\
\hline $\mathbf{8}$ & Increase with high slope & Increase with high slope & $\left(\boldsymbol{N}_{\boldsymbol{t}}\right)$ Increasing the number of tubes \\
\hline $\mathbf{9}$ & Decrease with high slope & Decrease with low slope & $(\boldsymbol{B} \boldsymbol{s})$ Increasing the distance of baffles \\
\hline $\mathbf{1 0}$ & Decrease with low slope & Decrease with low slope & $\left(\boldsymbol{l}_{\boldsymbol{c}} / \boldsymbol{D}_{\boldsymbol{s}}\right)$ Increasing the cutting of \\
baffles
\end{tabular}

In above table, steps of sensitive analysis related variables change on target functions are shown. Each of changes is shown in following figures.

In Figure 4. the effect of the pipe step ratio $(\mathrm{Pt} / \mathrm{N})$ is reflected on the heat transfer rate and the total cost of the heat exchanger. $\mathrm{Pt}$ is the center distance from the center of the two adjacent tubes in $\mathrm{mm}$. and do is outer diameter of tube in $\mathrm{mm}$. The allowed range of variation of this variable is between 1.25 and 2 in accordance with the Table 4 ., by changing this variable in this range, as shown in the following figure. As it can be seen, the effect of tube step on the cost is negligible while the effect on the transferred heat is relatively significant. Such that at the design point A by changing the pipe step ratio from 1.25 to 2 , the amount of transferred heat reduce from 420 to $390 \mathrm{~kW}(8.7 \%$ reduction). On the other hand, the total cost is reduced from $24500 \$$ to $23500 \$$ (less than $1 \%$ ). In justifying the above mentioned cases, it can be concluded that with increasing of pipe step, the velocity of the flow rate in the shell side decreases, and by reducing the heat transfer coefficient, the total heat transfer is reduced. Also due to the flow rate reduction on the shell side the pressure drops deceases and therefore the operational cost as well as the total cost are reduced.

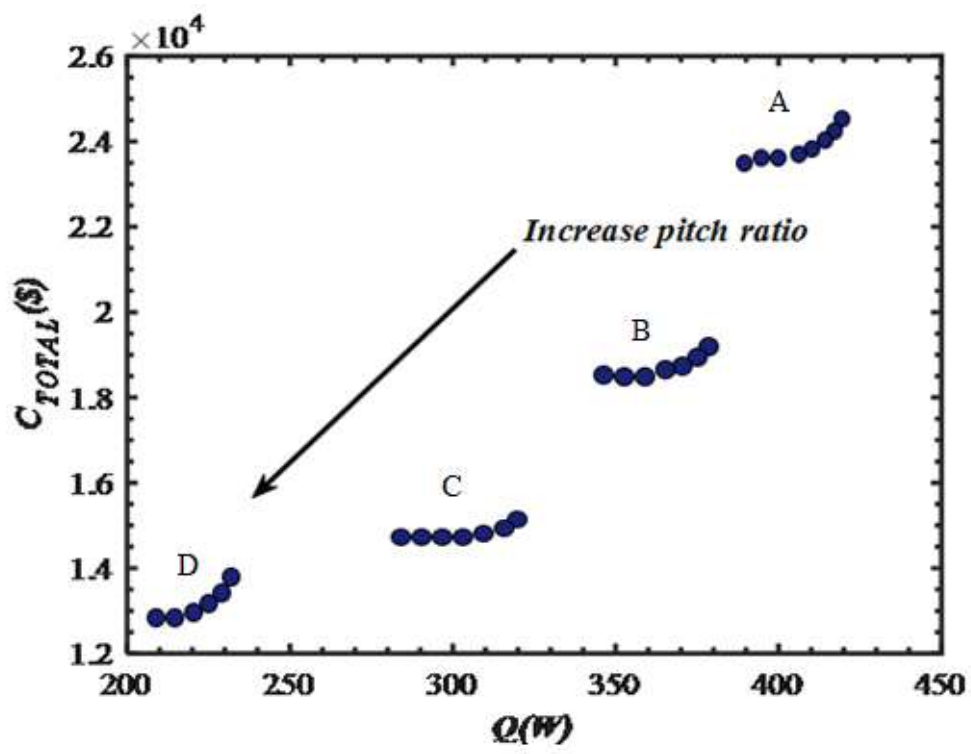

Figure 3. Effect of variable increase on the cost and heat transferred functions 
In Figure 4., the cost and heat transfer curve is plotted when the length of the tube varies from 3 to $12 \mathrm{~m}$. As it shows, at point A with increasing the length of the pipe from 3 to $12 \mathrm{~m}$, the heat transfer rate increases from 365 to $415 \mathrm{~kW}$ ( $13.7 \%$ increase), while the total cost increases from $20000 \$$ to $24500 \$(22 \%$ increase). As it is expected, the effect of the increase of pipe length is significant. Because by the increase of the pipe length and surface of the heat exchanger, increasing the cost of operation and investment. So for selection of best point, we have a choice that how much cost we can pay for increasing the heat transfer.

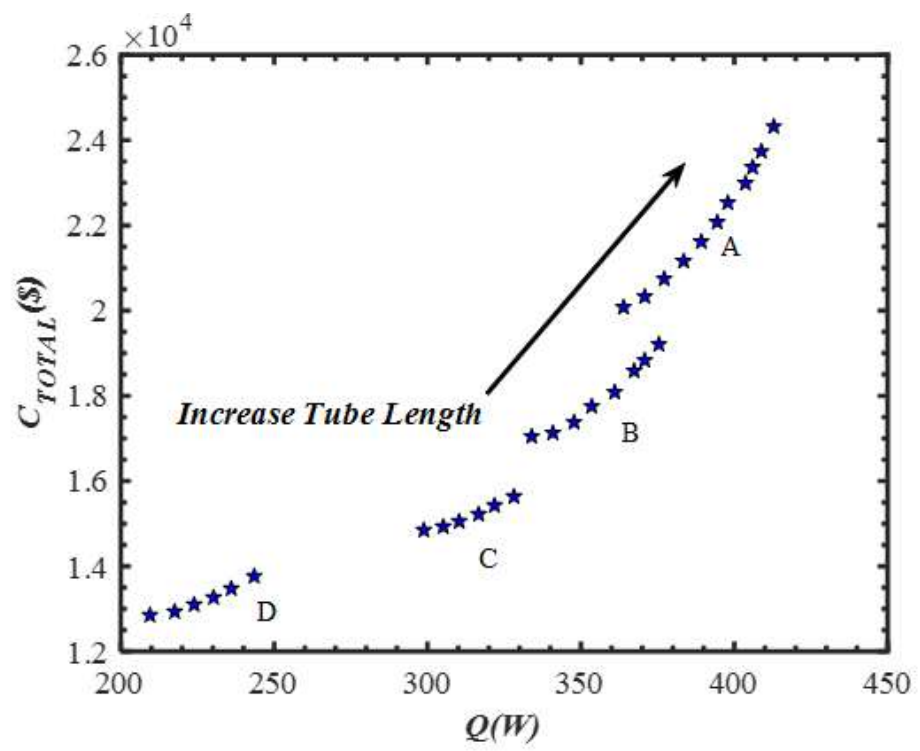

Figure 4. Effect of increasing the variable on cost and heat transfer rate

The analysis outcomes of the number of tubes are approximately similar with the analysis related to the length of the tube, as it is plotted in Figure 5. The cost and transferred heat curve when the number of tubes varies from 50 to 400 . As it is shown, increasing the number of tubes increases the heat transfer rate and the cost as well. The increase in the number of tubes increases the surface area of the heat exchanger and increases the cost of purchase and investment. This increase is more considerable for point $\mathrm{D}$ that has a lower cost and heat transfer.

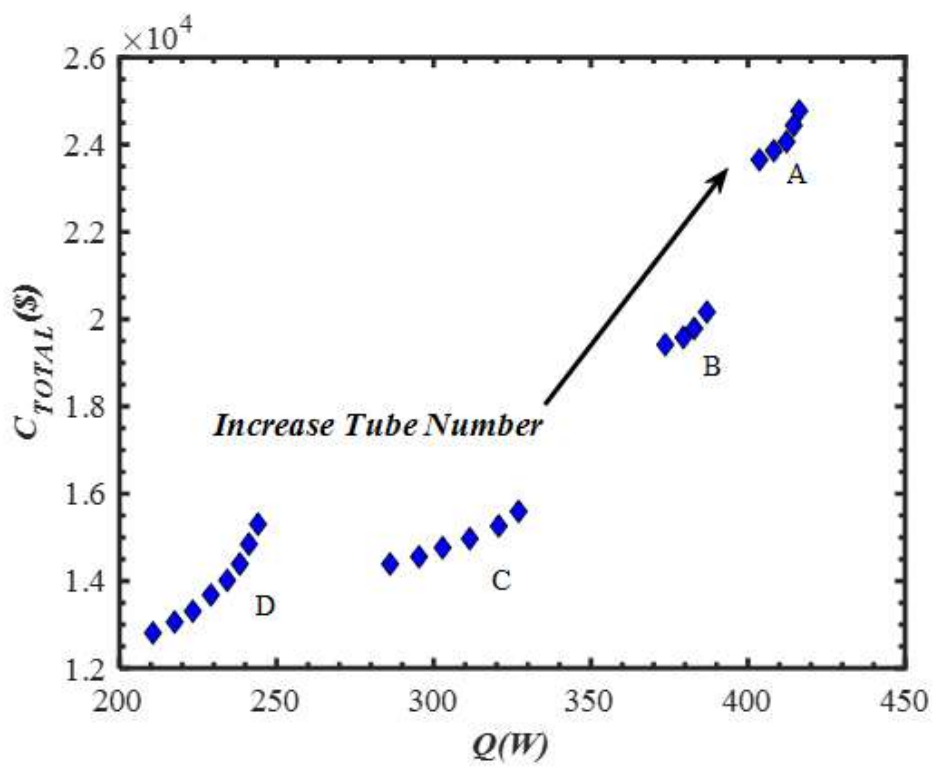

Figure 5. Effect of increasing the variable on cost and heat transfer 
In Figure 6. with the increase of baffle space distance, the cost as well as heat transfer rate in the heat exchanger is decreased due to increasing the baffle distance and therefore the flow disturbance is reduced. Moreover, increasing baffle distance causes the decrease in flow disturbance and decreases the pressure drop as well as the operational cost. At the point A, by increasing baffle distance from $20 \%$ to $140 \%$ of the shell diameter, the heat transfer rate is reduced to $6.25 \%$ and the reduction cost is reduced $5.5 \%$.

Figure 7. shows the effect of baffle cut. As it is shown, this variable has little effect on the cost and heat transfer rate. With increase of the baffle cut due to reduce flow disturbance the pressure drop is reduced lead to the reduction of the total cost. At the point $\mathrm{A}$, by increasing the baffle cut from $20 \%$ to $32 \%$ of the shell diameter, heat transfer rate and cost is decreased by $2.5 \%$ and $2 \%$, respectively.

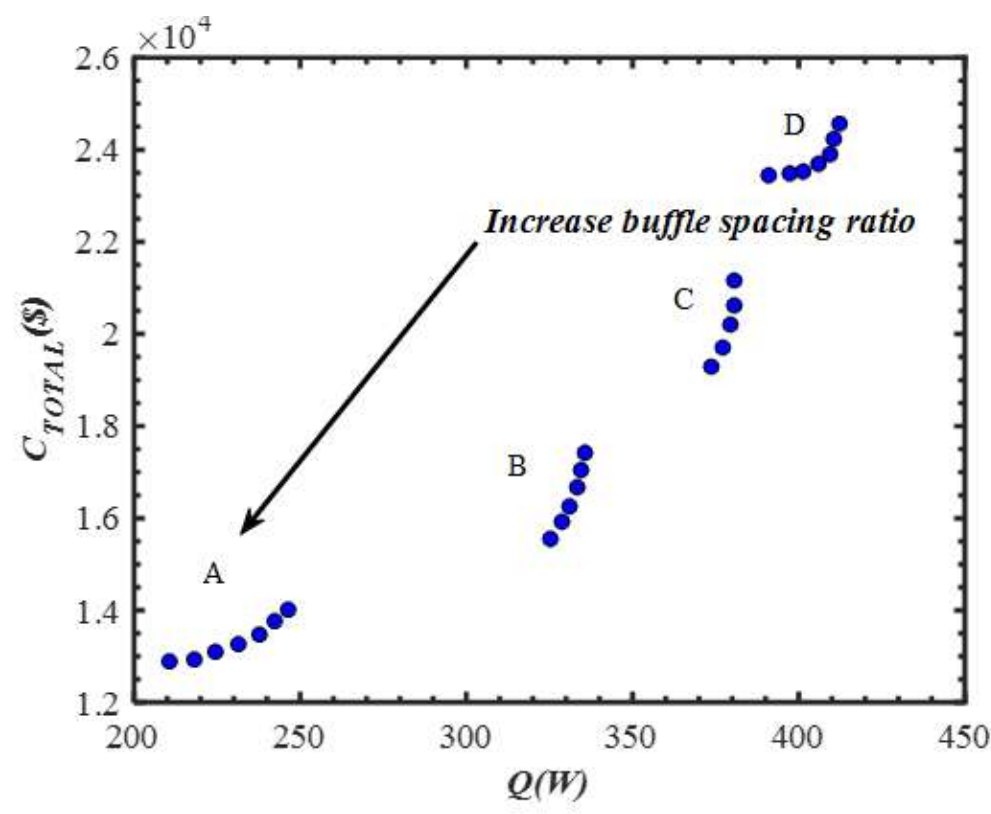

Figure 6. Effect of variable increase on cost and heat transfer

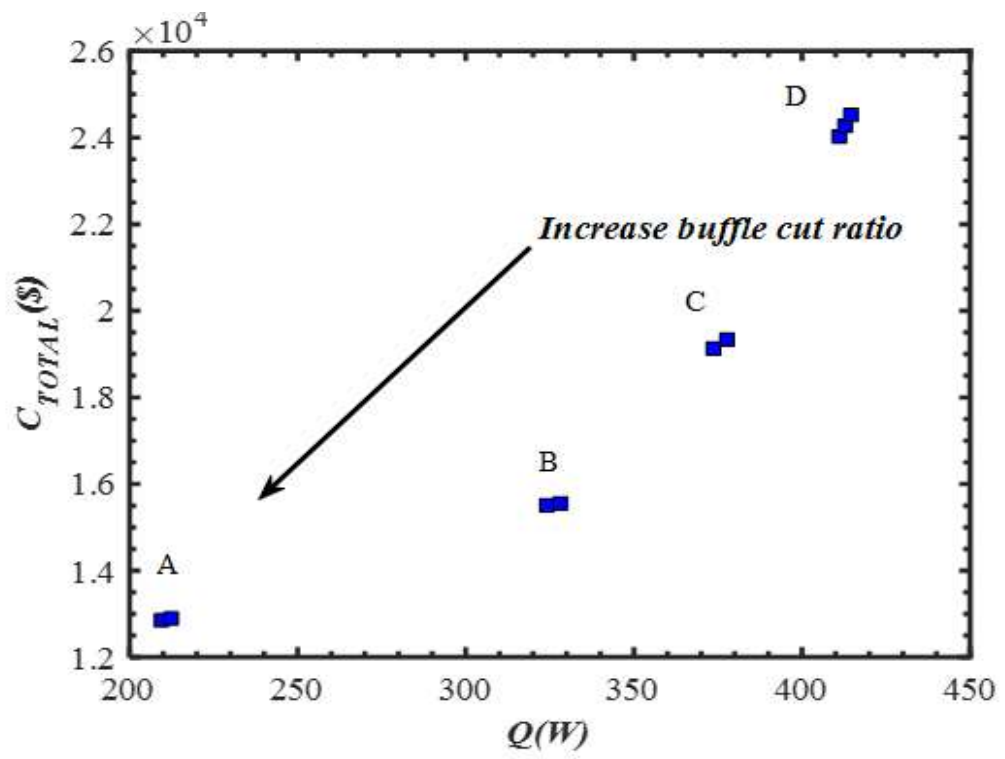

Figure 7. Effect of variable increase on cost and heat transfer 


\section{CONCLUSION}

In this paper, the two objective optimization of the shell and tube heat exchanger were carried out by considering six decision variables (pipe pitch, tube diameter, tube length, baffle ratio and baffle distance) with the assistance of the PSO algorithm. Optimization of heat exchanger with this algorithm give a view to user to select the best answer considering heat transfer and heat exchanger costs.

The modeling and optimization results were as follows:

- Modeling results of mathematical approaches were well matched to the actual results (data collected from the evaporator unit of the Tehran refinery's absorption chiller). The error rate in the pipeline pressure drops and the shell, was calculated at about $6 \%$ and $8 \%$ respectively, and the error rate in the prediction of heat transfer between the hot and cold fluid at about $5 \%$.

- The ratio of tube step to tube diameter had a slight effect on the cost while its effect on heat transfer rate was relatively significant (the allowable range of this variable was between 1.25 and 2).

- The analysis of the number of tubes, approximately similar with the length of the tube. When the number of tubes varied from 50 to 400 , increased the heat transfer rate and the cost as well. The increase in the number of tubes increased the surface area of the heat exchanger and increased the cost of purchase and investment.

- By the increase of baffle space distance, the cost as well as heat transfer rate in the heat exchanger were decreased due to increasing the baffle distance and therefore the flow disturbance was reduced. Moreover, increasing baffle distance caused the decrease in flow disturbance and decreases the pressure drop as well as the operational cost.

- The effect of baffle cut had little effect on the cost and heat transfer rate. With increase of the baffle cut due to reduce flow disturbance the pressure drop was reduced lead to the reduction of the total cost.

- By increase the pitch ratio from 1.25 to 2, the heat transfer was reduced from 420 to $390 \mathrm{~kW}$ about $7.8 \%$.

- Increasing the pipe length from 3 to $12 \mathrm{~m}$, the heat transfer rate raised from 365 to $415 \mathrm{~kW}$ by $13.7 \%$, while the cost increased from $20,000 \$$ to $24500 \$$ about $22 \%$.

\section{NOMENCLATURE}

B Baffle spacing (m)

do Tube outside diameter $(\mathrm{m})$

L Tube length (m)

$\mathrm{N} \quad$ Number of rows

$\operatorname{Pr} \quad$ Reduced pressure (pa/psat)

Q Heat load (W)

\section{Greek Symbols}

$\mu \quad$ Dynamic viscosity (Pa s)

$\rho \quad$ Density $\left(\mathrm{kg} / \mathrm{m}^{3}\right)$

$\eta \quad$ Pumping efficiency

\section{Subtitle}

b Bulk

f Fluid

i Inlet 


$\begin{array}{cl}\text { o } & \text { Outlet } \\ 1 & \text { Liquid } \\ \text { g } & \text { Gas } \\ \text { s } & \text { Shell } \\ \text { t } & \text { Tube } \\ \text { w } & \text { Wall }\end{array}$

\section{REFERENCES}

[1] Caputo AC, Pelagagge PM, Salini P. Manufacturing cost model for heat exchangers optimization. Applied Thermal Engineering. 2016;94:513-33.

[2] Ehyaei MA. Estimation of condensate mass flow rate during purging time in heat recovery steam generator of combined cycle power plant. Thermal Science. 2014;18(4):1389-97.

[3] Mozafari A, Ehyaei MA. Effects of Regeneration Heat Exchanger on Entropy, Electricity Cost, and Environmental Pollution Produced by Micro Gas Turbine System. International Journal of Green Energy. 2012;9(1):51-70.

[4] Sadeghzadeh H, Aliehyaei M, Rosen MA. Optimization of a Finned Shell and Tube Heat Exchanger Using a Multi-Objective Optimization Genetic Algorithm. Sustainability. 2015;7(9):11679-95.

[5] Sadeghzadeh H, Ehyaei M, Rosen M. Techno-economic optimization of a shell and tube heat exchanger by genetic and particle swarm algorithms. Energy Conversion and Management. 2015;93:84-91.

[6] Shah RK, Sekulic DP. Fundamentals of heat exchanger design. 2003.

[7] Yang J, Fan A, Liu W, Jacobi AM. Optimization of shell-and-tube heat exchangers conforming to TEMA standards with designs motivated by constructal theory. Energy Conversion and Management. 2014;78:468-76.

[8] Yang J, Oh S-R, Liu W. Optimization of shell-and-tube heat exchangers using a general design approach motivated by constructal theory. International Journal of Heat and Mass Transfer. 2014;77:1144-54.

[9] Aliehyaei M, Atabi F, Khorshidvand M, Rosen MA. Exergy, economic and environmental analysis for simple and combined heat and power IC engines. Sustainability. 2015;7(4):4411-24.

[10] Asgari E, Ehyaei M. Exergy analysis and optimisation of a wind turbine using genetic and searching algorithms. International Journal of Exergy. 2015;16(3):293-314.

[11] Ashari G, Ehyaei M, Mozafari A, Atabi F, Hajidavalloo E, Shalbaf S. Exergy, economic, and environmental analysis of a PEM fuel cell power system to meet electrical and thermal energy needs of residential buildings. Journal of Fuel Cell Science and Technology. 2012;9(5):051001.

[12] Shamoushaki M, Ehyaei M, Ghanatir F. Exergy, economic and environmental analysis and multi-objective optimization of a SOFC-GT power plant. Energy. 2017;134:515-31.

[13] Shamoushaki M, EHYAEI MA. EXERGY, ECONOMIC, AND ENVIRONMENTAL (3E) ANALYSIS OF A GAS TURBINE POWER PLANT AND OPTIMIZATION BY MOPSO ALGORITHM. Thermal Science. 2018;22(6A):2641-51.

[14] Shamoushaki M, Ghanatir F, Ehyaei M, Ahmadi A. Exergy and exergoeconomic analysis and multi-objective optimisation of gas turbine power plant by evolutionary algorithms. Case study: Aliabad Katoul power plant. International Journal of Exergy. 2017;22(3):279-307.

[15] Rao RR, Shrinivasa U, Srinivasan J. Synthesis of Cost-Optimal Shell-and-Tube Heat Exchangers. Heat Transfer Engineering. 1991;12(3):47-55.

[16] Caputo AC, Pelagagge PM, Salini P. Heat exchanger design based on economic optimisation. Applied Thermal Engineering. 2008;28(10):1151-9.

[17]Fesanghary M, Damangir E, Soleimani I. Design optimization of shell and tube heat exchangers using global sensitivity analysis and harmony search algorithm. Applied Thermal Engineering. 2009;29(5):1026-31.

[18] Özçelik Y. Exergetic optimization of shell and tube heat exchangers using a genetic based algorithm. Applied Thermal Engineering. 2007;27(11):1849-56.

[19] Ponce-Ortega JM, Serna-González M, Jiménez-Gutiérrez A. Use of genetic algorithms for the optimal design of shell-and-tube heat exchangers. Applied Thermal Engineering. 2009;29(2):203-9.

[20]Ponce-Ortega JM, Serna-González M, Salcedo-Estrada LI, Jiménez-Gutiérrez A. Minimum-Investment Design of Multiple Shell and Tube Heat Exchangers Using a MINLP Formulation. Chemical Engineering Research and Design. 2006;84(10):905-10. 
[21] Ravagnani MASS, Caballero JA. Optimal heat exchanger network synthesis with the detailed heat transfer equipment design. Computers \& Chemical Engineering. 2007;31(11):1432-48.

[22] Bejan A, Tsatsaronis G, Moran MJ. Thermal design and optimization. 1996.

[23] Johannessen E, Nummedal L, Kjelstrup S. Minimizing the entropy production in heat exchange. International Journal of Heat and Mass Transfer. 2002;45(13):2649-54.

[24] Sun S-y, Lu Y-d, Yan C-q. Optimization in calculation of shell-tube heat exchanger. International Communications in Heat and Mass Transfer. 1993;20(5):675-85.

[25] Allen B, Savard-Goguen M, Gosselin L. Optimizing heat exchanger networks with genetic algorithms for designing each heat exchanger including condensers. Applied Thermal Engineering. 2009;29(16):3437-44.

[26] Guo J, Cheng L, Xu M. Optimization design of shell-and-tube heat exchanger by entropy generation minimization and genetic algorithm. Applied Thermal Engineering. 2009;29(14):2954-60.

[27] Hilbert R, Janiga G, Baron R, Thévenin D. Multi-objective shape optimization of a heat exchanger using parallel genetic algorithms. International Journal of Heat and Mass Transfer. 2006;49(15):2567-77.

[28] Liu Z, Cheng H. Multi-objective optimization design analysis of primary surface recuperator for microturbines. Applied Thermal Engineering. 2008;28(5):601-10.

[29] Ozkol I, Komurgoz G. Determination of the Optimum Geometry of the Heat Exchanger Body Via A Genetic Algorithm. Numerical Heat Transfer, Part A: Applications. 2005;48(3):283-96.

[30] Selbaş R, Kızılkan Ö, Reppich M. A new design approach for shell-and-tube heat exchangers using genetic algorithms from economic point of view. Chemical Engineering and Processing: Process Intensification. 2006;45(4):268-75.

[31] Liu C, Bu W, Xu D. Multi-objective shape optimization of a plate-fin heat exchanger using CFD and multiobjective genetic algorithm. International Journal of Heat and Mass Transfer. 2017;111:65-82.

[32] Lu B, Wu J, Liang Z, Liu C. Circuitry arrangement optimization for multi-tube phase change material heat exchanger using genetic algorithm coupled with numerical simulation. Energy Conversion and Management. 2018;175:213-26.

[33] Patel VK, Rao RV. Design optimization of shell-and-tube heat exchanger using particle swarm optimization technique. Applied Thermal Engineering. 2010;30(11):1417-25.

[34] Dastmalchi M, Sheikhzadeh GA, Arefmanesh A. Optimization of micro-finned tubes in double pipe heat exchangers using particle swarm algorithm. Applied Thermal Engineering. 2017;119:1-9.

[35] Şencan Şahin A, Kılıç B, Kılıç U. Design and economic optimization of shell and tube heat exchangers using Artificial Bee Colony (ABC) algorithm. Energy Conversion and Management. 2011;52(11):3356-62.

[36]Zarea H, Kashkooli FM, Soltani M, Rezaeian M. A novel single and multi-objective optimization approach based on Bees Algorithm Hybrid with Particle Swarm Optimization (BAHPSO): Application to thermal-economic design of plate fin heat exchangers. International Journal of Thermal Sciences. 2018;129:552-64.

[37] Azad AV, Amidpour M. Economic optimization of shell and tube heat exchanger based on constructal theory. Energy. 2011;36(2):1087-96.

[38] Rao RV, Patel V. Multi-objective optimization of heat exchangers using a modified teaching-learning-based optimization algorithm. Applied Mathematical Modelling. 2013;37(3):1147-62.

[39]Fettaka S, Thibault J, Gupta Y. Design of shell-and-tube heat exchangers using multiobjective optimization. International Journal of Heat and Mass Transfer. 2013;60:343-54.

[40] Wildi-Tremblay P, Gosselin L. Minimizing shell-and-tube heat exchanger cost with genetic algorithms and considering maintenance. International Journal of Energy Research. 2007;31(9):867-85.

[41]Lv J, Jiang X, He G, Xiao W, Li S, Sengupta D, et al. Economic and system reliability optimization of heat exchanger networks using NSGA-II algorithm. Applied Thermal Engineering. 2017;124:716-24.

[42] Yang H, Wen J, Wang S, Li Y. Thermal design and optimization of plate-fin heat exchangers based global sensitivity analysis and NSGA-II. Applied Thermal Engineering. 2018;136:444-53.

[43] Rao RV, Patel VK. Thermodynamic optimization of cross flow plate-fin heat exchanger using a particle swarm optimization algorithm. International Journal of Thermal Sciences. 2010;49(9):1712-21.

[44]Rao RV, Saroj A. Constrained economic optimization of shell-and-tube heat exchangers using elitist-Jaya algorithm. Energy. 2017;128:785-800.

[45]Rao RV, Saroj A. Economic optimization of shell-and-tube heat exchanger using Jaya algorithm with maintenance consideration. Applied Thermal Engineering. 2017;116:473-87.

[46] Vasconcelos Segundo EHd, Amoroso AL, Mariani VC, Coelho LdS. Economic optimization design for shelland-tube heat exchangers by a Tsallis differential evolution. Applied Thermal Engineering. 2017;111:143-51.

[47] Majid Etghani M, Amir Hosseini Baboli S. Numerical investigation and optimization of heat transfer and exergy loss in shell and helical tube heat exchanger. Applied Thermal Engineering. 2017;121:294-301. 
[48] Raja BD, Jhala RL, Patel V. Many-objective optimization of shell and tube heat exchanger. Thermal Science and Engineering Progress. 2017;2:87-101.

[49] Raja BD, Jhala RL, Patel V. Thermal-hydraulic optimization of plate heat exchanger: A multi-objective approach. International Journal of Thermal Sciences. 2018;124:522-35.

[50] Raja BD, Patel V, Jhala RL. Thermal design and optimization of fin-and-tube heat exchanger using heat transfer search algorithm. Thermal Science and Engineering Progress. 2017;4:45-57.

[51] Turgut O. Thermal and Economical Optimization of a Shell and Tube Evaporator Using Hybrid Backtracking Search - Sine Cosine Algorithm. Arabian Journal for Science and Engineering. 2017;42.

[52]Kern DQ. Process heat transfer: Tata McGraw-Hill Education; 1950.

[53] Gungor KE, Winterton R. A general correlation for flow boiling in tubes and annuli. International Journal of Heat and Mass Transfer. 1986;29(3):351-8.

[54] Cooper M. Heat flow rates in saturated nucleate pool boiling-a wide-ranging examination using reduced properties. Advances in heat transfer. 16: Elsevier; 1984. p. 157-239 10.1016/s0065-2717(08)70205-3.

[55] Coello CAC, Lechuga MS, editors. MOPSO: a proposal for multiple objective particle swarm optimization. Proceedings of the 2002 Congress on Evolutionary Computation CEC'02 (Cat No02TH8600); 2002 12-17 May 2002.

[56] Daily and monthly reports of Compression Chillers of Tehran oil refinery. National Iranian Oil Company; 2017. 